\title{
Avaliação do Estresse Térmico causado em Operador de Caldeira: Um estudo sobre a Saúde no Ambiente Laboral
}

\author{
Marlize Reffatti Zinelli'; Paulo Fernando do Nascimento Martins²; Aline Buzzo da Costa ${ }^{3}$; \\ Lauriano Antônio Barella ${ }^{4}$
}

\begin{abstract}
Resumo: O presente estudo teve como objetivo avaliar o estresse térmico em que o operador de caldeira fica exposto e os métodos de evitar tal problema nas indústrias madeireiras no município de Alta Floresta, Mato Grosso. Para tanto, a metodologia empregada foi de acordo com a Norma de Higiene Ocupacional - NHO 06, usando o medidor de estresse térmico digital portátil modelo TGD-200. A coleta de dados foi realizada em 3 empresas de beneficiamento de madeira que utilizam caldeira para suas atividades. Os resultados indicaram que os valores IBTUG estão acima do permitido pela legislação o que torna os ambientes de trabalho insalubres. De fato, é de grande importância que os empresários tomem conhecimento desse problema para se enquadrem nas normas e assim evitem um dano a saúde dos trabalhadores.
\end{abstract}

Palavras-chave: IBTUG, Higiene Ocupacional, Medidor de Estresse, Trabalho Insalubre.

\section{Thermal Stress Assessment on Boiler Operator: A study on Health at Workplace Environment}

\begin{abstract}
This study aimed to evaluate the thermal stress on the operator is exposed boiler and methods to avoid this problem in the lumber industries in the municipality of Alta Floresta, Mato Grosso. Therefore, the methodology used was in accordance with the Standard Occupational Hygiene - NHO 06, using the thermal stress meter portable digital model TGD-200. Data collection was performed in 3 wood processing companies that use boiler for their activities. The results indicated that the values IBTUG then above those permitted by law which makes it unhealthy work environments. In fact, it is very important that business owners are aware of this problem for fitting the standards and thus avoid harm to workers' health.
\end{abstract}

Keyword: IBTUG, Occupational Hygiene, Meter Stress, Unhealthy Work

\section{Introdução}

O processamento mecânico da madeira remonta aos primórdios do ser humano, e seu desenvolvimento acompanhou a evolução da civilização humana, partindo dos primeiros instrumentos rudimentares, até chegar aos equipamentos computadorizados da atualidade (ALBUQUERQUE, 1995).

\footnotetext{
${ }^{1}$ Msc.Eng. ${ }^{a}$ Florestal, FADAF; Docente da Faculdade de Direito de Alta Floresta - MT; lize.zinelli@ yahoo.com.br

${ }^{2}$ Eng. Florestal, Universidade do Estado de Mato Grosso-UNEMAT/Alta Floresta.pauloafl@ hotmail.com.

${ }^{3}$ Eng. ${ }^{a} \quad$ Segurança do Trabalho, Alta Floresta, MT. eng.alinebuzzo@ hotmail.com

${ }^{4}$ Msc.Contador, FADAF; Docente da Faculdade de Direito de Alta Floresta - MT, barella28@ hotmail.com
} 
Caldeiras a vapor são equipamentos destinados a produzir e acumular vapor sob pressão superior à atmosférica, utilizando qualquer fonte de energia, excetuando-se os refervedores e equipamentos similares utilizados em unidades de processo (MTE, 1978).

A caldeira tem um papel muito importante nas empresas de beneficiamento de madeira, pois usa os resíduos para gerar vapor que alimentam as máquinas, diminuindo assim o consumo de energia da empresa, além de aproveitar os resíduos.

A ergonomia representa um campo fundamental para a melhoria das condições de trabalho nas mais diversas atividades profissionais, proporcionando conforto e segurança para o trabalhador e aumentando sua produtividade (SANTOS, 1997).

Para Dul e Weerdmeester (1995), a ergonomia tem sua origem na linguagem Grega, e significa: ergon (trabalho) e nomos (regras, normas e leis).

Segundo Iida (2005) ambiente de trabalho é composto por um conjunto de fatores interdependentes, que atuam direta ou indiretamente na qualidade de vida dos trabalhadores e nos resultados do próprio trabalho grande fonte de tensão no trabalho são as condições ambientais desfavoráveis, como excesso de calor, ruídos e vibrações.

O calor tem sido amplamente utilizado nas indústrias atualmente, principalmente naquelas que lidam com substâncias sólidas como os metais, que são facilmente fundidos a altas temperaturas. Nestas indústrias são liberadas quantidades enormes de energia calorífica nos processos, submetendo seus funcionários a condições de intenso calor. Seu efeito sobre o ser humano pode variar com a sua intensidade, com a exposição prolongada e também com as características individuais dos trabalhadores (SOUZA, 2003).

Segundo a NR-15, anexo n.3 (MTE, 1978), temperaturas extremas podem ter influência sobre o trabalhador no seu posto de trabalho. O problema pode ser originado pela exposição ao calor produzido por fontes radiantes, correntes de convecção ou por condução. O calor, ao contrário dos outros agentes físicos, como pressões anormais, as radiações e o ruído, é mais difícil de ser avaliado com precisão, tendo em vista a grande variedade de fatores ambientais e individuais que influem na sensação térmica (SOUZA, 2003).

Alguns fatores endógenos podem também desafiar a estabilidade térmica, sendo a atividade muscular o mais importante. O exercício físico aumenta o metabolismo, aumentando consideravelmente a produção de calor. Conforme a intensidade do esforço 
físico e as condições ambientais, a temperatura corporal central pode elevar-se a níveis prejudiciais à saúde (KROEMER; GRANDJEAN, 2005).

Neste sentido, indivíduos que se exercitam ou trabalham em ambientes muito quentes enfrentam desafios fisiológicos que podem comprometer o desenvolvimento de suas atividades e, ainda, podem ser acometidos por lesões térmicas sérias e até risco de vida. $\mathrm{O}$ armazenamento de calor e a consequente elevação da temperatura corporal central a níveis críticos acarretam na incidência de doenças térmicas, em especial a exaustão térmica e o EHS (Exertional Heat Stroke), duas formas de insolação que atingem tanto atletas quanto trabalhadores expostos a situações de estresse térmico (GAMBRELL, 2002). No presente estudo, objetivou-se avaliar o estresse térmico ocupacional causado pela caldeira.

\section{Material e Métodos}

O método através do qual se efetuou a avaliação térmica foi o do Índice de Bulbo Úmido - Termômetro de Globo (IBUTG). O equipamento utilizado bem como os procedimentos adotados para a execução das medições foram os recomendados pela norma NHO - 06 da FUNDACENTRO. Para Saliba (2000), o índice de temperatura de bulbo úmido termômetro de globo (IBUTG) foi desenvolvido inicialmente como um método simples para avaliar a sobrecarga térmica em contingentes militares. Também permite o cálculo de períodos adequados de trabalho-descanso, no caso em que o índice ultrapasse os limites estabelecidos. Legislação brasileira, através da Portaria n.3.214 de 08/06/78, estabelece que a exposição ao calor deve ser avaliada por meio do IBUTG. Consiste em um índice de sobrecarga térmica, definido por uma equação matemática que correlaciona alguns parâmetros medidos no ambiente de trabalho. O valor de IBUTG obtido e o metabolismo estimado para atividade no local de trabalho são comparados aos limites de exposição estabelecidos pelas normas técnicas especificas.

O índice de Bulbo Úmido Termômetro de Globo - IBUTG leva em consideração todos os fatores ambientais e fisiológicos do equilíbrio homeotérmico e, atualmente, é utilizado pela ACGIH (American Conference of Governmental Industrial Hygienists), NIOSH (National Institute for Occupational Safety and Health) e NR- 15. 
Os valores do IBUTG são calculados da seguinte forma:

Ambientes internos ou externos sem carga solar: $\mathrm{IBUTG}=0,7 \mathrm{Tbn}+0,3 \mathrm{Tg}$

Sendo:

IBUTG = índice de bulbo úmido termômetro de globo

Tbn = temperatura de bulbo úmido natural

$\mathrm{Tg}=$ temperatura do globo

O medidor de stress térmico mod. TGD-200 marca INSTRUTHERM, é um equipamento compacto, preciso e de fácil operação. Composto de Indicador e MóduloSensor com 3 Sondas, indica o stress térmico, Bulbo Seco, Bulbo Úmido e efetua o cálculo de IBUTG Interno e Externo.

Figura 1: Medidor de stress térmico mod. TGD-200 marca INSTRUTHERM

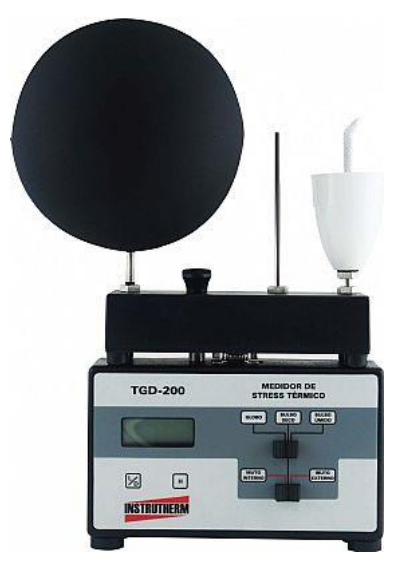

Fonte: http://www.thermodin.com.br

Tanto o indicador, quanto o conjunto Módulo/Indicador, podem ser adaptados à um tripé com altura regulável. 
Figura 2: Medidor de stress térmico adaptado ao tripé.

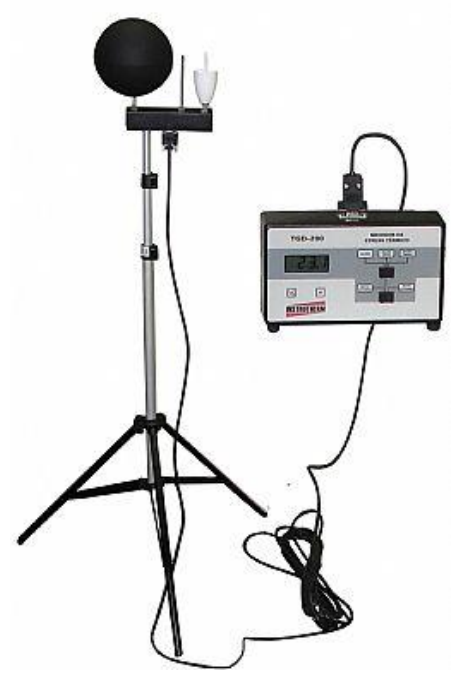

Fonte: http://www.thermodin.com.br

As medições foram realizadas no mês de novembro de 2016 em três empresas que utilizam caldeira para o processo de beneficiar madeira no município de Alta Floresta - MT, a altura da região do corpo mais atingida, através da utilização de tripé regulável, conforme estabelece a NR15 anexo 03 .

O intervalo entre cada ponto avaliado respeitou um tempo mínimo de 20 min, para estabilização do termômetro de maior tempo, foram realizadas 5 leituras até que o valor ficasse estável.

\section{Resultados e Discussão}

Analisou-se o Stress Térmico através da medição com o equipamento Medidor de Stress Térmico Modelo TGD-200 Digital da Instrutherm Instrumentos de Medição, através do Índice de Bulbo Úmido e Termômetro de Globo - IBUTG. A equação a ser utilizada em ambiente interno sem carga solar conforme determina a Norma Regulamentadora 15 em seu anexo $n^{\text {a }} 3$. 
Tabela1: Leituras realizadas de temperatura de bulbo úmido natural e temperatura do globo.:

\begin{tabular}{cllllll}
\hline & \multicolumn{2}{c}{ Empresa 1 } & \multicolumn{2}{c}{ Empresa 2 } & \multicolumn{2}{c}{ Empresa 3 } \\
& Tbn & $\mathrm{Tg}$ & $\mathrm{Tbn}$ & $\mathrm{Tg}$ & $\mathrm{Tbn}$ & Tg \\
Evento 1 & 29,00 & 28,80 & 30,70 & 28,50 & 30,70 & 30,10 \\
Evento 2 & 29,20 & 28,70 & 31,30 & 28,20 & 31,50 & 30,40 \\
Evento 3 & 29,30 & 28,80 & 30,00 & 28,10 & 31,30 & 30,50 \\
Evento 4 & 29,30 & 28,80 & 31,00 & 28,20 & 31,20 & 30,40 \\
Evento 5 & 29,30 & 28,80 & 31,00 & 28,20 & 31,20 & 30,40 \\
Média & $\mathbf{2 9 , 2 0}$ & $\mathbf{2 8 , 8 0}$ & $\mathbf{3 0 , 8 0}$ & $\mathbf{2 8 , 2 0}$ & $\mathbf{3 1 , 2 0}$ & $\mathbf{3 0 , 4 0}$ \\
\hline
\end{tabular}

Fonte: Autores (2017)

IBUTG $=0,7 \times$ tbn $+0,3 \times$ tg

Onde: $\mathrm{IBUTG}=\mathrm{tbn}=$ Temperatura de Bulbo Úmido, $\operatorname{tg}=$ Temperatura de Globo

Tabela 2: com resultado do IBUTG das empresas avaliadas:

\begin{tabular}{cc}
\hline & IBUT \\
Empresa 01 & 29,08 \\
Empresa 02 & 30,02 \\
Empresa 03 & 30,96 \\
\hline
\end{tabular}

Fonte: Autores (2017)

Considerando que o tipo de trabalho do operador de caldeira é moderado, de acordo com a tabela 3 taxas de metabolismo por tipo de atividade disponível no quadro 3 do anexo ${ }^{\circ}$ 3 da Norma Regulamentadora 15. 
Id on Line Revista Multidisciplinar e de Psicoloqia

Id on Line Multidisciplinary and Psycology Journal

Tabela 3: Taxas de metabolismo por tipo de atividade

\section{TIPO DE ATIVIDADE}

$\mathrm{Kcal} / \mathrm{h}$

Sentado em repouso

TRABALHO LEVE

Sentado, movimentos moderados com braços e tronco (ex. Datilografia).

Sentado, movimentos moderados com braços e pernas (ex.: dirigir).

De pé, trabalho leve, em máquina ou bancada, principalmente com os braços.

\section{TRABALHO MODERADO}

Sentado, movimentos vigorosos com braços e pernas.

De pé, trabalho leve em máquina ou bancada, com alguma movimentação.

De pé, trabalho moderada em máquina ou bancada, com alguma movimentação.

Em movimento, trabalho moderado de levantar ou empurrar.

\section{TRABALHO PESADO}

Trabalho intermitente de levantar, empurrar ou arrastar pesos (ex.: remoção com pá).

Trabalho fatigante.

Fonte: anexo n 3 da Norma Regulamentadora 15

A tabela 4 que mostra a relação do tipo de atividade e o tempo de trabalho disponível no quadro $n^{\circ} 1$ do anexo $n^{\circ} 3$ da Norma Regulamentadora 15, observa-se que o regime de trabalho intermitente com descanso no próprio local de trabalho (por hora) conforme o ocorrido nas industrias madeireiras estudadas o IBUTG máximo é de 26,70 para a atividade moderada.

\section{Tabela 4: Tipo de atividade}

\begin{tabular}{|c|c|c|c|}
\hline \multirow{2}{*}{$\begin{array}{l}\text { Regime de trabalho intermitente com descanso } \\
\text { no próprio local de trabalho (por hora) }\end{array}$} & \multicolumn{3}{|c|}{ Tipo de atividade } \\
\hline & Leve & Moderada & Pesada \\
\hline Trabalho contínuo & Até 30,0 & Até 26,7 & Até 25,00 \\
\hline 45 minutos trabalho 15 minutos de descanso & 30,10 a 30,60 & 26,80 a 28,00 & 25,10 a 25,90 \\
\hline 30 minutos trabalho 30 minutos de descanso & 30,70 a 31,40 & 28,10 a 29,40 & 26,00 a 27,90 \\
\hline 15 minutos trabalho 45 minutos de descanso & 31,50 a 32,20 & 29,50 a 31,10 & 28,00 a 30,00 \\
\hline $\begin{array}{l}\text { Não é permitido o trabalho sem a adoção de } \\
\text { medidas adequadas de controle. }\end{array}$ & Acima 32,20 & $\begin{array}{r}\text { Acima de } \\
31,10\end{array}$ & $\begin{array}{r}\text { Acima de } \\
30,00\end{array}$ \\
\hline
\end{tabular}


Todas as empresas avaliadas tiveram a aferição do IBUTG acima de 26,70 sendo assim, acima do limite permitido, ambiente insalubre. Na empresa 01, o valor de IBUTG foi de 29,08, o funcionário deve trabalhar 30 minutos e ter 30 minutos de descanso, na Empresa 2 o valor IBUTG encontrado foi 30,02 com esse valor o ideal seria que o operador de caldeira trabalhe 15 minutos e tenha 45 minutos de descanso, já na Empresa 3 o IBUTG chegou no valor de 30,96 sendo recomendado o trabalho de 15 minutos e 45 minutos de descanso.

Pode-se observar que o ambiente em estudo encontrava-se insalubre, afetando a qualidade de vida do trabalhador. Por este motivo, é necessária a alteração do regime de trabalho ou a utilização de equipamentos de proteção.

Uma forma de proteção coletiva para amenizar o calor é através da ventilação adequada, ou seja, não apenas a circulação de ar, mas também a introdução de ar fresco no ambiente ou a eliminação de ar quente e úmido, se as fontes são localizadas. Isto pode ser obtido por meio de ventilação natural ou mecânica e deve projetar-se, de tal modo, que não produzam correntes fortes. Deve-se estar seguro de que o ar introduzido tenha menor temperatura que o ar existente no ambiente de trabalho.

Se mesmo assim não for amenizado o problema, os trabalhadores expostos devem usar equipamentos de proteção individuais que amenizem os efeitos do calor, como camisas com cores claras, aventais ou jalecos em material refletivo, além do tempo de descanso recomendado pela norma. É fundamental que as empresas disponibilizem água fresca suficiente para beber, localizada em lugar conveniente. Portanto, é de suma importância seguir as recomendações da legislação, visando garantir segurança e conforto aos trabalhadores e empreendedores.

\section{Conclusões}

A partir do levantamento quantitativo dos níveis de calor das três empresas, os resultados obtidos foram analisados e comparados com os níveis máximos de exposição exigidos pela norma regulamentadora NR 15 . 
Constatou-se que os ambientes de trabalho na caldeira das empresas proporcionam situação de exposição acima do recomendado em legislação, mas que podem ser controlados com a ação preventiva de equipamentos de proteção individual e coletivo.

\section{Referências}

ACGIH. Industrial hygiene, environmental, occupational health. Disponível em: <http://www.acgih.org >. Acesso em: março. 2017.

ALBUQUERQUE, C. E. C. de. Processamento mecânico da madeira na evolução humana. Revista da Madeira, Curitiba, v. 4, n. 23, p. 36-37, 1995.

BRASIL. Norma Regulamentadora 15. Portaria ${ }^{\circ}$ 3.214, de 08 de junho de 1978 Ministério do Trabalho e Emprego. Diário Oficial da República Federativa do Brasil, Brasília.

DUL, J. e WEERDMEESTER, B. Ergonomia Prática. São Paulo. Edgard Bliicher ltda, 1995.

GAMBRELL, R. C. Doenças térmicas e exercício. In: LILLEGARD, W. A.; BUTCHER, J.

D.; RUCKER, K. S.. Manual de medicina desportiva: uma abordagem orientada aos sistemas. São Paulo, SP: Manole, 2002. p. 457-464.

IIDA, I. Ergonomia: projeto e produção. São Paulo: Edgard Blucher; 2005. 614p.

KROEMER, K. H. E.; GRANDJEAN, E. Manual de ergonomia: adaptando o trabalho ao homem. 5.ed.. São Paulo, SP: Bookman, 2005.

Ministério do Trabalho e Emprego. Norma de Higiene Ocupacional - NHO 06: Avaliação da Exposição ao Calor. São Paulo: FUNDACENTRO, 2002.

SALIBA, Tuffi Messias. Manual prático de avaliação e controle de calor: PPRA. São Paulo: LTr, 2000.

SANTOS, N. Manual de Análise Ergonômica no Trabalho. 2. ed.. Curitiba: Genesis, 1997.

SouZA, S. GUElli U, M. A. Apostila do Curso de Engenharia de Segurança do Trabalho -Sobrecarga Térmica e Temperaturas Baixas. Universidade Federal de Santa Catarina: Florianópolis, 2003. 
Id on Line Revista Multidisciplinar e de Psicoloqia

Id on Line Multidisciplinary and Psycology Journal

THERMODIN. Instrumentos de medição. Disponível em: http://www.thermodin.com.br. Acesso em: agosto. 2017.

Como citar este artigo (Formato ABNT):

ZINELli, Marlize R.; MARTINS, Paulo F N.; COSTA, Aline B; BARELLA, L.A. Avaliação do Estresse Térmico causado em operador de caldeira: Um estudo sobre a Saúde no Ambiente Laboral. Id on Line Revista Multidisciplinar e de Psicologia, 2017, vol.11, n.37, p. 308-317. ISSN: 1981-1179.

Recebido: 24.08.2017

Aceito: 27.08 .2017 